\title{
Basal Forebrain Cholinergic-induced Activation of Cholecystokinin Inhibitory Neurons in the Basolateral Amygdala
}

\author{
Seungho Lee and Joung-Hun Kim* \\ Department of Life Sciences, Pohang University of Science and Technology (POSTECH), Pohang 37673, Korea
}

\begin{abstract}
The basolateral amygdala (BLA) receives dense projections from cholinergic neurons of the basal forebrain. Acetylcholine can contributes to amygdala-dependent behaviors: formation and extinction of fear memory and appetitive instrumental learning. However, the cholinergic mechanism at the circuit level has not been defined yet. We demonstrated that cholinergic-induced di-synaptic inhibition of BLA pyramidal neurons exhibits a retrograde form of short-term synaptic inhibition, depolarization-induced suppression of inhibition (DSI). Activation of nicotinic receptors was sufficient to evoke action potentials in cholecystokinin (CCK)-positive inhibitory neurons, which strongly inhibit pyramidal neurons through their perisomatic synapses. Our cell type-specific monosynaptic retrograde tracing also revealed that CCK neurons are innervated by basal forebrain cholinergic neurons. Therefore, our data indicated that CCK inhibitory neurons mediate the cholinergic-induced di-synaptic inhibition of BLA pyramidal neurons.
\end{abstract}

Key words: Cholecystokinin, Acetylcholine, Di-synaptic inhibition, Basolateral amygdala, Iontophoresis, Retrograde tracing

\section{INTRODUCTION}

Acetylcholine is one of few neurotransmitters that can act both on metabotropic (muscarinic) and ionotropic (nicotinic) receptors. The slow action (through G-protein-coupled receptor, GPCR) of muscarinic acetylcholine receptor (mAChR) regulates neuronal excitability, presynaptic release probability, and synaptic plasticity [1]. On the other hand, the nicotinic acetylcholine receptor (nAChR) functions as a non-selective cation channel that directly depolarizes dendrites, cell bodies, and axons of neurons, which results in evoking neuronal firing as well as potentiating

Received April 22, 2019, Revised May 28,2019,

Accepted May 31, 2019

* To whom correspondence should be addressed. TEL: 82-54-279-2347, FAX: 82-54-279-5969

e-mail: joungkim@postech.ac.kr the release of various neurotransmitters depending upon their targets [2]. $\mathrm{nAChR}$ is prominently expressed on a subset of inhibitory neurons in the hippocampus and supragranular layers of the neocortex $[3,4]$. Furthermore, di-synaptic inhibition induced by the activation of cholinergic fibers has been reported in pyramidal neurons in the sensorimotor cortex and amygdala $[5,6]$.

The basolateral amygdala (BLA) receives dense cholinergic inputs arising primarily from the basal forebrain (BF) [7]. Consistent with dense cholinergic projections, acetylcholine released from $\mathrm{BF}$ plays a pivotal role in BLA-dependent behaviors: formation and extinction of fear memory and appetitive instrumental learning [8-11]. At the cellular level, acetylcholine can primarily suppress BLA pyramidal neurons by direct activation of postsynaptic $\mathrm{mA}$ ChR $[5,8]$, although intense activation (e.g., $20 \mathrm{~Hz}$ stimulation for a few seconds) induces excitation following suppression $[8,9]$. On the other hand, nAChR also modulates the activity of pyramidal neurons indirectly through neighboring inhibitory neurons rather
Copyright $\odot$ Experimental Neurobiology 2019. www.enjournal.org
This is an Open Access article distributed under the terms of the Creative Commons Attribution Non-Commercial License (http://creativecommons.org/licenses/by-nc/4.0) which permits unrestricted non-commercial use, distribution, and reproduction in any medium, provided the original work is properly cited. 
than directly acting on the BLA pyramidal neurons themselves [5]. However, which cells and micro-circuits are recruited for nicotinic suppression of BLA pyramidal neurons remains unknown.

Cholecystokinin (CCK)-expressing inhibitory neurons are a major subtype of basket cells in BLA. CCK neurons are endowed with various receptors for mood-associated neuromodulators such as serotonin, endocannabinoids, noradrenaline, neuropeptide $Y$, and acetylcholine [12]. Acetylcholine can excite CCK neurons through the $\alpha 7$ and $\alpha 4$ nicotinic receptors in the hippocampus [13] and neocortex [14], respectively. mAChR also activates CCK inhibitory neurons in the hippocampus [15]. Bursts of inhibitory currents on CA1 pyramidal neurons evoked by the activation of cholinergic fibers was suppressed by depolarization-induced suppression of inhibition (DSI), which is mediated by cannabinoid receptor type 1 (CB1R) located in the presynapses of CCK inhibitory neurons [16]. However, it is unknown whether BLA CCK inhibitory neurons respond to acetylcholine.

In the present study, to delineate the BLA micro-circuits underlying the cholinergic actions, we used optogenetic tools to specifically activate BF cholinergic inputs and ex vivo patch clamp recordings from BLA neurons in acute slices. This approach enabled us to measure the di-synaptic inhibitory currents from BLA pyramidal neurons achieved through activation of the nicotinic receptor. We found that this was sensitive to DSI and that iontophoretic application of acetylcholine induces robust firing of CCK inhibitory neurons. Subsequent cell type-specific retrograde tracing revealed that BLA CCK inhibitory neurons were heavily innervated by BF cholinergic neurons. Taken together, these results provide evidence that BF cholinergic-induced di-synaptic inhibition of BLA pyramidal neurons is mediated by CCK inhibitory neurons.

\section{MATERIALS AND METHODS}

\section{Animals}

Male mice were derived from breeders in our laboratory's animal facility. ChAT(BAC)-Cre mice (RRID: MMRRC_030869UCD) were originally obtained from the MMRRC (Davis, CA) and bred in transgenic $\mathrm{x}$ wild-type mating pairs. CCK-IRES-Cre mice (RRID:IMSR_JAX: 012706) were obtained from the Jackson Laboratory (Bar Harbor, ME) and bred as homozygote $\mathrm{x}$ wildtype. The mice were housed with a 12-hour light/dark cycle and given ad libitum access to food and water. All procedures involving animals were approved by the ethical review committee of POSTECH (Pohang University of Science \& Technology), Korea and performed in accordance with relevant guidelines.

\section{Viral vectors}

AAV1-EF1a-DIO-hChR2(H134R)-EYFP was purchased from the University of North Carolina, Gene Therapy Center (Chapel Hill, NC). AAV5-hDlx-DIO-EYFP-2A-TVA $\left(2.2 \times 10^{13} \mathrm{GC} /\right.$ $\mathrm{ml})$ and AAV9-hDlx-DIO-oG $\left(1.2 \times 10^{13} \mathrm{GC} / \mathrm{ml}\right)$ were produced [17] with pXR5 or pXR9, pAd $\triangle F 6$, and pAAV vectors that were subcloned using pAAV-hDlx-DIO-eGFP (\#83895, Addgene, Watertown, MA) for the pAAV-hDlx-DIO backbone vector, pAAV-DIO-hGTB (\#26196, Addgene) for the TVA insert, and pAAV-CAG-fDIO-oG (\#74291, Addgene) for the oG (modified rabies glycoprotein) insert. Pseudo-typed rabies virus EnvA-RVmCherry $\left(1.3 \times 10^{8} \mathrm{IU} / \mathrm{ml}\right)$ was produced using the BHK-EnvA cell line and rabies virus (SAD B19) was obtained from Callaway (Salk Institute for Biological Studies, CA) in accordance with established protocols [18].

\section{Viral delivery}

Mice were anesthetized with a ketamine and xylazine cocktail and positioned in a stereotaxic apparatus (Kopf, Tujunga, CA). For viral infections, $0.15 \sim 0.3 \mu \mathrm{l}$ of virus solution was infused into each hemisphere with Nanoject III (Drummond Scientific, Broomall, $\mathrm{PA}$ ) at a rate of $1 \mathrm{nl} / \mathrm{sec}$ after waiting $5 \mathrm{~min}$ from the insertion of the glass needle. The glass needle was kept in place for an additional 10 min. For photostimulation of BF cholinergic fibers in ex vivo recording configurations, AAV1-EF1a-DIO-hChR2(H134R)-EYFP $(0.3 \mu \mathrm{l})$ was delivered bilaterally to the basal forebrain including the substantia innominata (SI) and the diagonal band nucleus (NDB) of ChAT-Cre mice at the following coordinates: AP +0.4 $\mathrm{mm}, \mathrm{ML} \pm 1.6 \mathrm{~mm}$, and DV $-5.5 \mathrm{~mm}$ from the bregma, and then subject mice were incubated for 4 weeks. To identify CCK inhibitory neurons for ex vivo electrophysiological experiments, AAV5hDlx-DIO-EYFP-2A-TVA $(0.15 \mu \mathrm{l})$ was delivered to the BLA at the following coordinates: AP $-1.2 \mathrm{~mm}, \mathrm{ML} \pm 3.3 \mathrm{~mm}, \mathrm{DV}-4.6$ $\mathrm{mm}$ from the bregma, and then subject mice were incubated for 2 weeks. These BLA coordinates were also used in the retrograde monosynaptic tracing experiment. For cell-type specific retrograde monosynaptic tracing, 0.15 0.2 $\mu$ l of AAV5-hDlx-DIOEYFP-2A-TVA and AAV9-hDlx-DIO-oG mix (1:1) was injected into the BLA of CCK-IRES-Cre mice. After a 2-week incubation, $0.4 \mu \mathrm{l}$ of EnvA-pseudotyped rabies virus (EnvA-RV-mCherry) was injected into the same site, and then was left for 5 10 days to allow for the rabies virus to spread trans-synaptically and express its associated fluorescent protein.

\section{Immunohistochemistry}

Brains were obtained after transcardial perfusion using cold PBS followed by $4 \%$ paraformaldehyde (PFA) and post-fixed with $4 \%$ 
PFA at $4{ }^{\circ} \mathrm{C}$ overnight. For sectioning, the fixed brains were embedded in $4 \%$ agarose and sliced into $50 \mu \mathrm{m}$ thick coronal sections using a vibratome (VT1000S, Leica, Wetzlar, Germany). Sections were blocked and permeabilized with 6\% normal donkey serum (ab7475, Abcam) and 0.5\% Triton X-100 in PBS at room temperature (RT) for 1 2 hr. Free-floating sections were incubated at $4{ }^{\circ} \mathrm{C}$ for $48 \sim 60 \mathrm{hr}$ with a goat anti-ChAT primary antibody (1:500, AB144P, Millipore), mouse anti-GAD65 (1:500, MAB351, Millipore) and anti-GAD67 (1:500, MAB5406, Millipore) primary antibodies mix or a rabbit anti-CamK2 primary antibody (1:500, ab52476, Abcam) with 1\% normal donkey serum and $0.5 \%$ Triton X-100 in PBS, followed by a donkey anti-goat secondary antibody conjugated with Alexa 488 (1:500, A-11008, Invitrogen) for ChAT, a donkey anti-mouse DyLight 550 (1:500, SA5-10167, Invitrogen) for GAD or a donkey anti-rabbit Alexa 568 (1:500, A-10042, Invitrogen) for CamK 2 at $4{ }^{\circ} \mathrm{C}$ for $3 \mathrm{hr}$. Immunostained sections were mounted on slides with a DAPI-containing mounting medium
(SC-24941, Santa Cruz). Confocal imaging was performed using an Olympus FV3000 confocal microscope.

\section{Cell counting}

To identify CCK inhibitory neurons, AAV5-hDlx-DIOEYFP-2A-TVA $(0.15 \mu \mathrm{l})$ was delivered to the BLA. Mice were sacrificed after 2 weeks. Confocal imaging was performed using an Olympus FV3000 confocal microscope. ROIs were set on soma of each GFP+ neurons. Area $\left(\mu \mathrm{m}^{2}\right)$ was calculated by Olympus Fluoview FV31S-SW. $176 \mu \mathrm{m}^{2}$ in soma size (the size of cell with 15 $\mu \mathrm{m}$ in diameter) was used as the criteria [19] for classification of type L CCK and type S CCK neurons.

\section{Brain slice preparation}

Brains were removed from the skull and sliced into 350- $\mu \mathrm{m}$ thick sections using a vibratome in an ice-cold sucrose-based ACSF solution containing (in mM): 185 sucrose, $2.5 \mathrm{KCl}, 1.2 \mathrm{NaH}_{2} \mathrm{PO}_{4}, 10$
A

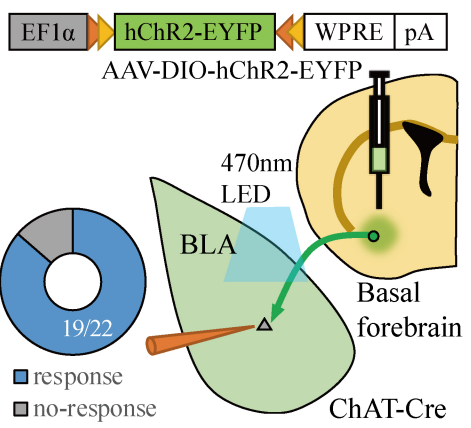

B

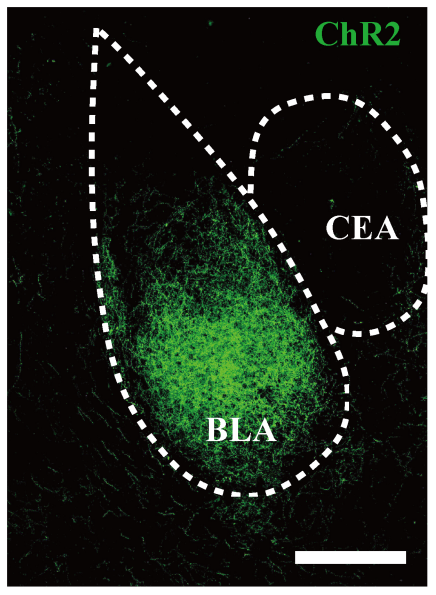

C

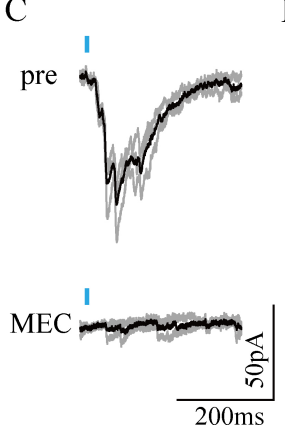

D

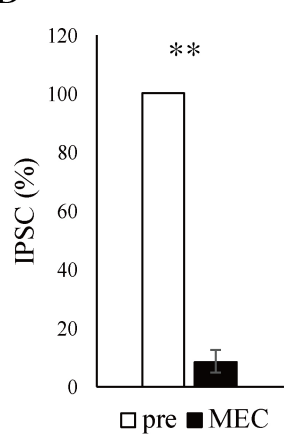

$\mathrm{E}$

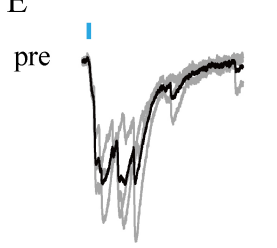

PTX

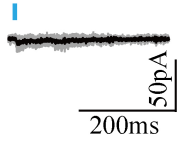

F

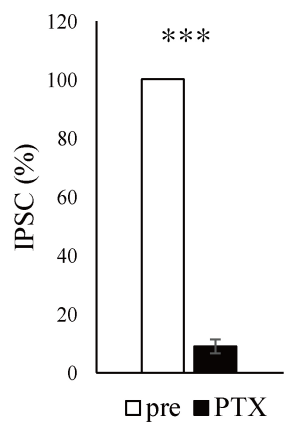

$\mathrm{G}$

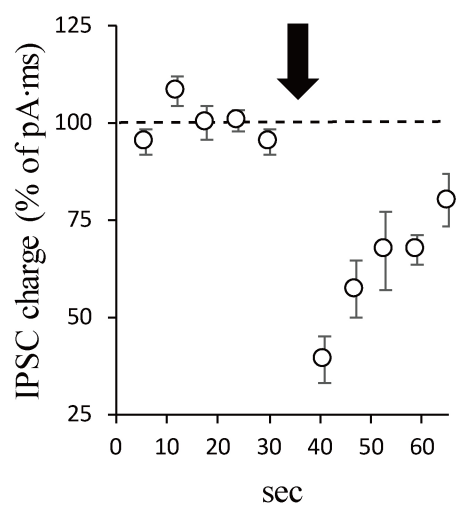

$\mathrm{H}$

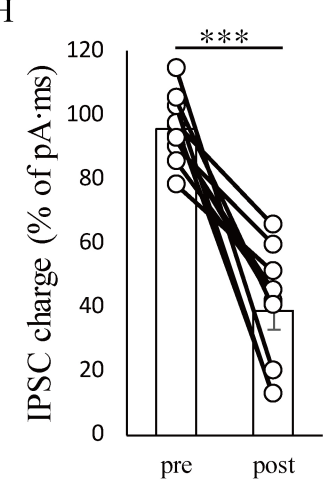

I
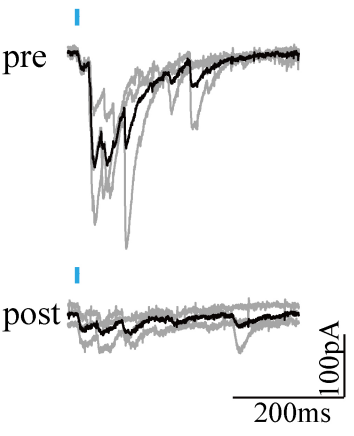

Fig. 1. Activation of BF cholinergic terminal induces di-synaptic IPSCs from BLA pyramidal neurons. (A) Viral expression of channelrhodopsin (H134R) in basal forebrain cholinergic neurons of ChAT-Cre mice. Optically-evoked IPSCs in most BLA pyramidal neurons ( $\mathrm{n}=22$ cells; $\mathrm{N}=5$ mice). (B) Expression of channelrhodopsin in the axon terminals in the BLA. Scale bar $=500 \mu \mathrm{m}$. (C, D) IPSCs (gray) and averaged (black) IPSC recorded BLA pyramidal neurons pre and post treatment with mecamylamine (MEC, $10 \mu \mathrm{M} ; \mathrm{n}=3$ cells; $\mathrm{N}=3$ mice; paired t-test $\mathrm{p}<0.01$ ). (E, F) IPSCs (gray) and averaged (black) IPSC recorded BLA pyramidal neurons pre and post treatment with picrotoxin, (PTX, $100 \mu \mathrm{M} ; \mathrm{n}=3$ cells; $\mathrm{N}=3$ mice; paired $\mathrm{t}$-test $\mathrm{p}<0.001$ ). (G) IPSCs recorded in BLA pyramidal neurons with the DSI protocol (black arrow). (H) Percentage of IPSC charges (pA.ms) pre and post DSI ( $\mathrm{n}=9$ cells; $\mathrm{N}=4$ mice; paired t-test $\mathrm{p}=0.0002$ ). (I) 3 IPSCs (gray) and averaged (black) IPSC pre and post DSI. BLA, basolateral amygdala; CEA, central amygdala. 
$\mathrm{MgSO}_{4}, 26 \mathrm{NaHCO}_{3}, 25$ glucose, $0.5 \mathrm{CaCl}_{2}$, and 1 ascorbate. Slices were then transferred to a holding chamber filled with prewarmed $\left(30 \sim 35^{\circ} \mathrm{C}\right)$ ACSF solution oxygenized with $95 \% \mathrm{O}_{2}, 5 \% \mathrm{CO}_{2}(\mathrm{pH}$ 7.3 7.4) containing the following (in $\mathrm{mM}$ ): $124 \mathrm{NaCl}, 2.5 \mathrm{KCl}$, $1.2 \mathrm{NaH}_{2} \mathrm{PO}_{4}, 2 \mathrm{MgSO}_{4}, 26 \mathrm{NaHCO}_{3}, 12.5$ glucose, $2 \mathrm{CaCl}_{2}$, and 1 ascorbate. The osmolarity of the ACSF was 300 mOsm. Thirty minutes after incubation, slices were additionally equilibrated at RT for 30 min prior to being transferred to the recording chamber.

\section{Ex vivo electrophysiological recording}

Acute brain slices were transferred to the recording chamber and superfused $(2 \mathrm{ml} / \mathrm{min}$ ) continuously with oxygenized ACSF. Sig-
A

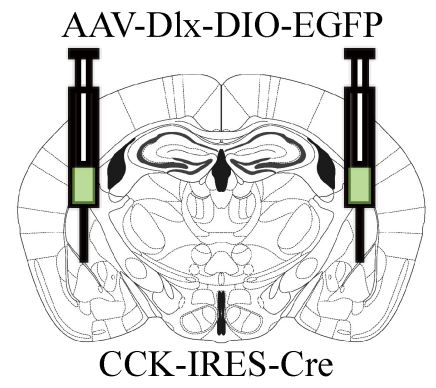

D

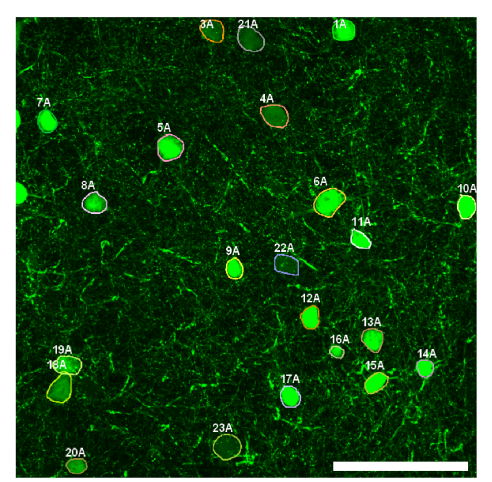

$\mathrm{B}$

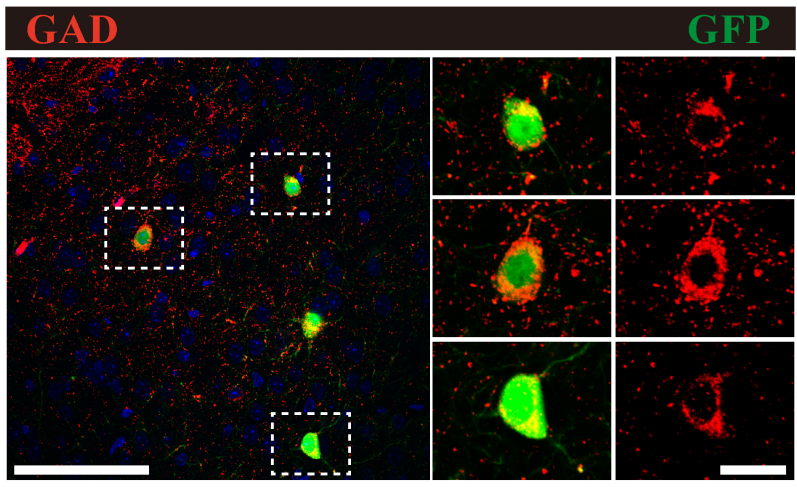

$\mathrm{C}$

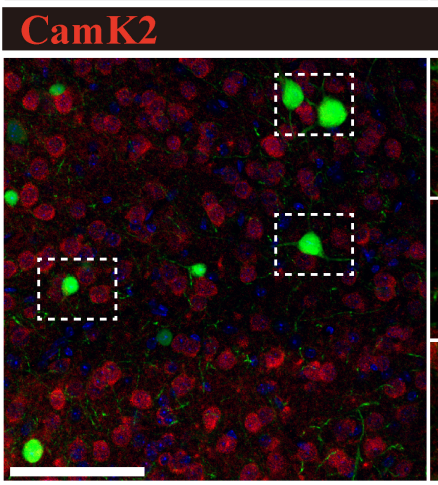

GFP
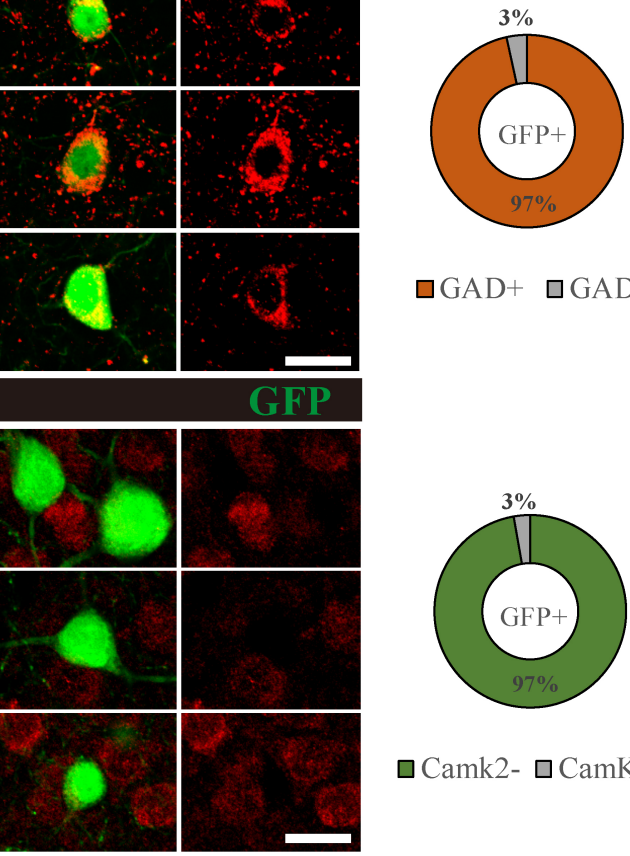

$\square \mathrm{GAD}+\square \mathrm{GAD}-$

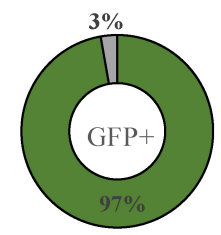

$\square$ Camk2- $\square$ CamK2+
E

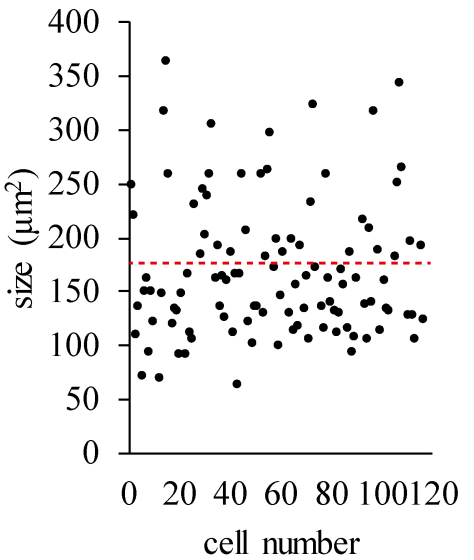

F

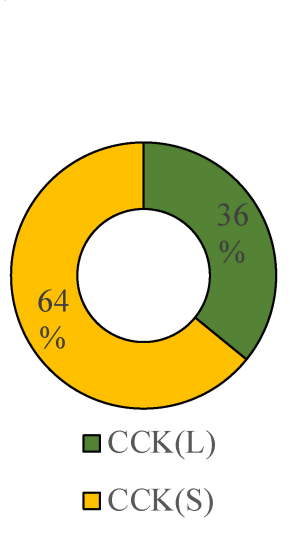

G

Fig. 2. Visualization of CCK inhibitory neurons in BLA. (A) Expression of eGFP in BLA CCK inhibitory neurons by using CCK-IRES-Cre mice and AAV-Dlx-DIO-eGFP vector. (B) Most eGFP positive neurons (green) are GAD (red) positive (97\%, 28/29) and (C) CamK2 (red) negative (97\%, 70/72) in BLA. Scale bar $=100 \mu \mathrm{m}$ (left), $20 \mu \mathrm{m}$ (right, magnified image). (D) ROIs are outlined in the boundary of soma of each GFP+ cells to calculate soma size. Scale bar $=100 \mu \mathrm{m}$. (E) Individual soma sizes are shown. $176 \mu \mathrm{m}^{2}$ (the size of cell with $15 \mu \mathrm{m}$ in diameter) is used as criteria (red dashed line) for classification of type L CCK and type S CCK neurons. (F) Type L CCK neurons (size > $176 \mu^{2}$ ) comprise 36\% of total CCK neurons ( 106 cells), and remained portion $(64 \%)$ are type S CCK neurons (size $<176 \mu^{2}$ ). (G) Soma size for each group is presented as median with 25th/75th percentiles (box) and 10th to 90 th percentiles (whiskers). 
nals were recorded with a MultiClamp 700B Amplifier (Molecular Devices). For IPSCs, patch electrodes with a resistance of 6 8 MW were filled with a high chloride internal solution containing the following (in mM): 145 CsCl, 1 EGTA, 10 HEPES, 2 Mg-ATP, 0.2 Na-GTP, and 5 QX-314 at pH 7.2. Drugs (e.g., NBQX $(10 \mu \mathrm{M})$, and atropine $(1 \mu \mathrm{M}))$ were treated through bath-application. Signals were evoked using a 470-nm LED light (M470L3, Thorlabs) at 90sec intervals. For the DSI protocol, the interval between stimuli was 6 sec and depolarization was induced every minute by holding the membrane potential at $0 \mathrm{mV}$ for $5 \mathrm{sec}$. For cell-attached patch recording, patch electrodes were filled with filtered ACSF. Neuronal firing was recorded in a loosely sealed state. For local administration of acetylcholine, an iontophoretic pipette was filled with acetylcholine (20 mM, No. 2809, Tocris) and placed within $20 \sim 30 \mu \mathrm{m}$ distant to target neurons. Constant current (-15 nA) was kept applied to prevent acetylcholine leakage. To release the acetylcholine, a brief positive current ( $200 \mathrm{nA}, 500 \mathrm{~ms}$ ) was applied at 90 -sec intervals. All recorded signals were analyzed using the Clampfit 10.4 software (Molecular Devices). All drugs used in the ex vivo recording experiments were purchased from Tocris except for atropine (Sigma, A0132) and MEC (Sigma, M9020).

\section{Statistics}

All whole-cell recording data were analyzed using paired twotailed t-tests. Cell-attached patch recording data was analyzed using one-way ANOVA. All statistical analyses were carried out using IBM SPSS statistics 21 . A level of significance $p<0.05$ was used. All data are represented as mean \pm standard error of the mean
$(\mathrm{SEM})$

\section{RESULTS AND DISCUSSION}

It is well known that the BLA receives dense projections from BF cholinergic neurons [7]. In order to measure electrophysiological responses of BLA pyramidal neurons to inputs from BF cholinergic neurons, we took advantage of transgenic choline acetyltransferase (ChAT)-Cre mice in which Cre is expressed in ChAT, a marker of cholinergic neurons, -containing neurons. The light-activated sodium channel, channelrhodopsin-2 (ChR2), was expressed in the cholinergic neurons of the $\mathrm{BF}$ region and their BLA axon terminals by injecting AAV (Fig. 1A). Consistent with previous reports, $\mathrm{BF}$ cholinergic axons densely innervated especially ventral part of the BLA (Fig. 1B). Then, we started to analyze the physiological responses elicited by the activation of ChAT axon terminals in the BLA. In acute brain slices, BLA pyramidal neurons were voltage-clamp recorded at $-70 \mathrm{mV}$ holding potential with a high chloride internal solution $(145 \mathrm{mM})$ to facilitate detection of IPSCs. AMPAR-mediated glutamatergic transmission was abolished by bath application of NBQX (10 $\mu \mathrm{M})$. Since pyramidal neurons in BLA are known to be suppressed or activated directly by muscarinic receptors $[5,8]$, whole-cell recording experiments were conducted in the presence of muscarinic acetylcholine receptor antagonist to exclude a direct effect of acetylcholine and thereby isolate di-synaptic events originated from local microcircuits. Optical stimulation ( $470 \mathrm{~nm}, 5 \mathrm{~ms}$ ) of BF cholinergic axons induced inhibitory postsynaptic currents (IPSCs) in BLA
A

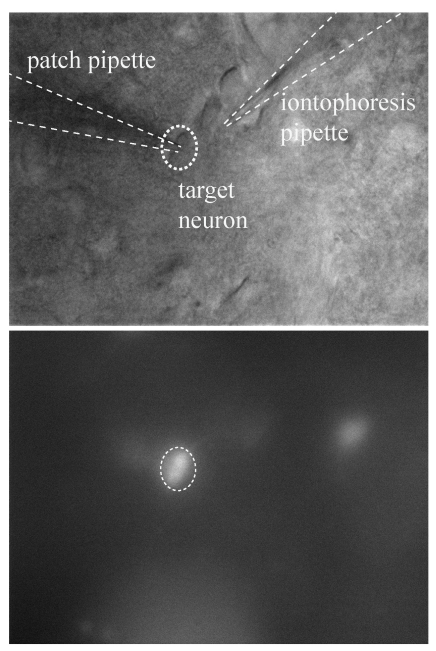

B acetylcholine $(20 \mathrm{mM})$

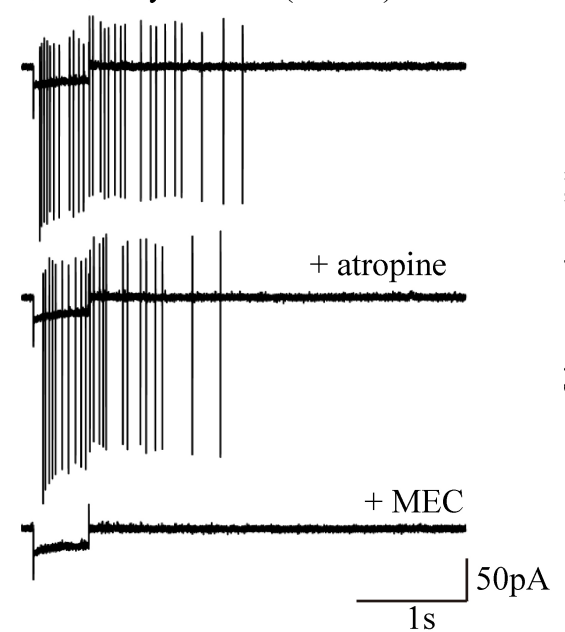

C

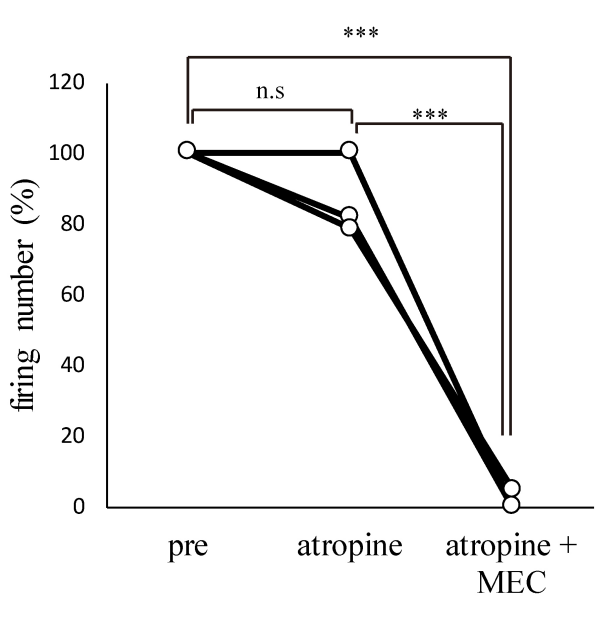

Fig. 3. Acetylcholine excites CCK inhibitory neurons by activation of nicotinic acetylcholine receptor. (A) Cell-attached patch performed on Dlx-DIOeGFP expressed neurons. (B) Firing of CCK inhibitory neurons induced by iontophoresis of acetylcholine. (C) Change in number of firings after drug treatment (atropine, $10 \mu \mathrm{M}$; MEC, $10 \mu \mathrm{M} ; \mathrm{n}=3$ cells; $\mathrm{N}=3$ mice; one-way ANOVA, $\mathrm{F}[2,6]=178.996, \mathrm{p}<0.001$ with Tukey's post-hoc test ${ }^{* * *} \mathrm{p}<0.001$ ). 
A

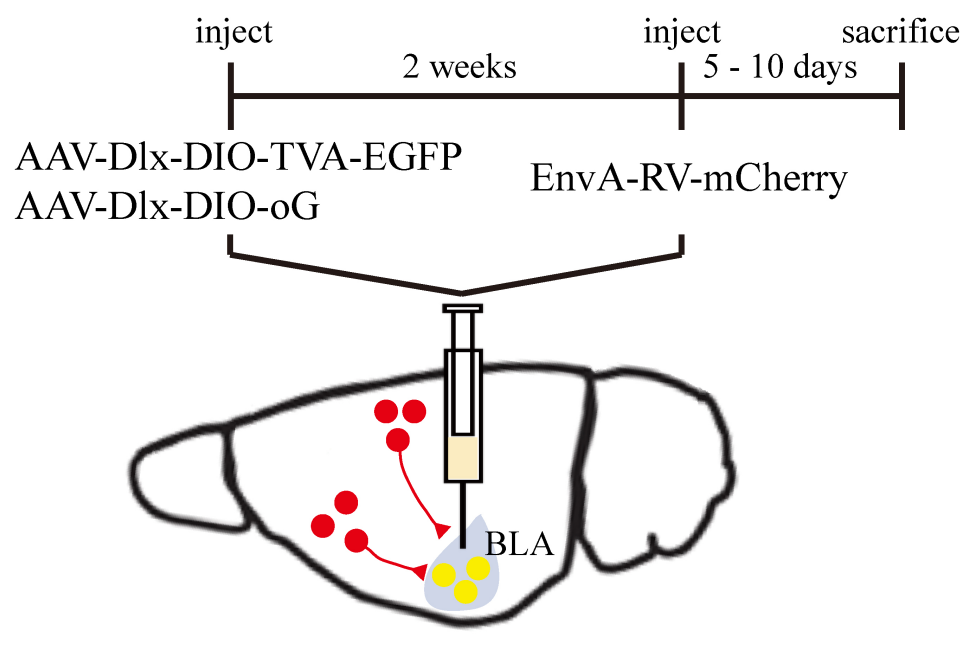

B

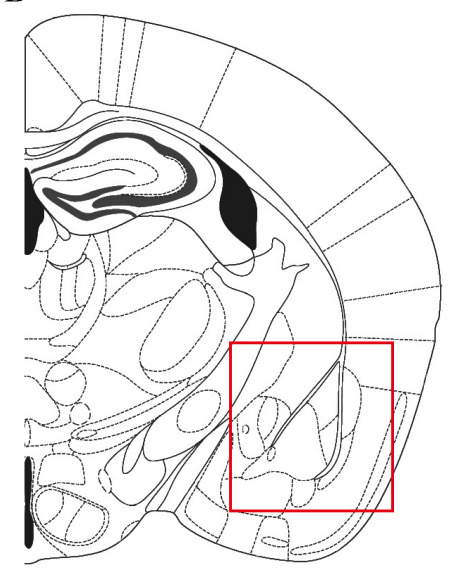

basolateral amygdala

Bregma, AP -1.2

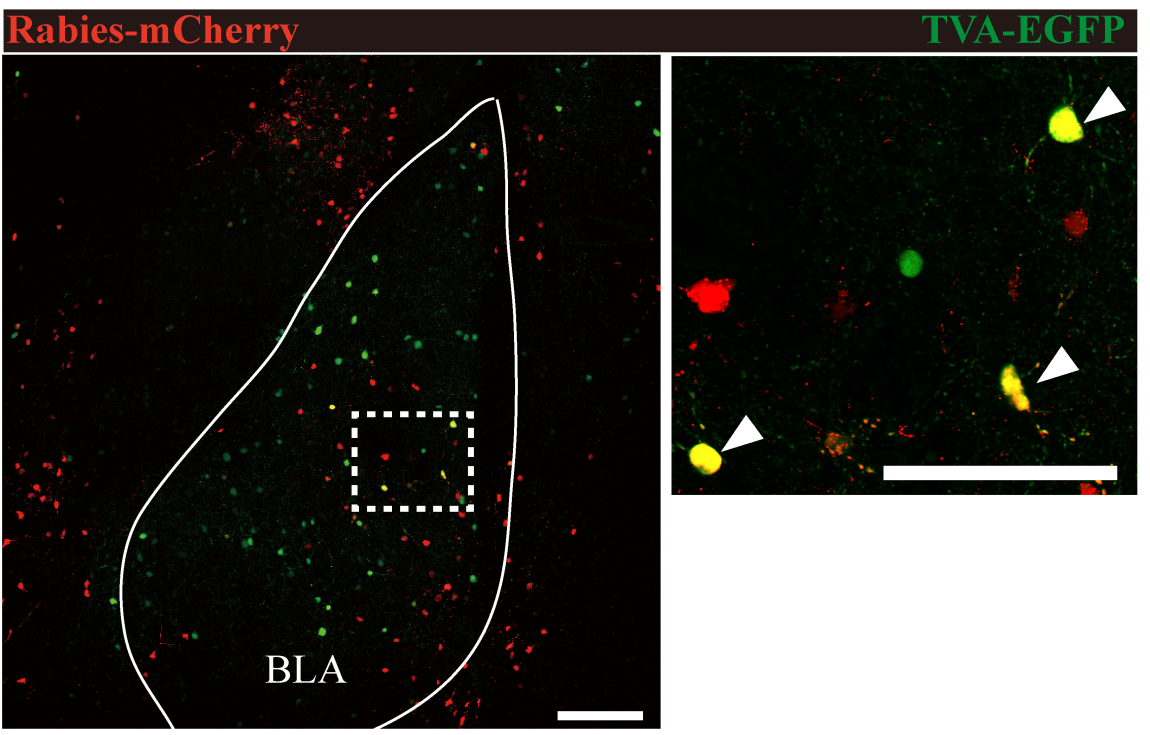

Fig. 4. Retrograde monosynaptic tracing from BLA CCK inhibitory neurons. (A) A experimental scheme. (B) Starter neurons (TVA-expressing neurons (green) infected with EnvA-RV-mCherry(red)) (white triangle) in the BLA. Scale bar=200 $\mu \mathrm{m}$ (left), $100 \mu \mathrm{m}$ (right, magnified image). (C) Retrogradetraced neurons (red) co-localized with ChAT (green) in the BF region. Scale bar=200 $\mu \mathrm{m}$ (left), $100 \mu \mathrm{m}$ (right, magnified image). BLA, basolateral amygdala; SI, substantia innominata; NDB, diagonal band nucleus.

pyramidal neurons (Fig. 1A, 1C and 1E). This was completely blocked by the bath application of non-selective nicotinic acetylcholine receptor antagonist [mecamylamine (MEC), $10 \mu \mathrm{M}$ ] (Fig. $1 \mathrm{C}$ and $1 \mathrm{D})$. Since most of the $\mathrm{nAChR}$ currents are carried by sodium and potassium which causes local depolarization [20] and the activation of $\mathrm{nAChR}$ induced excitatory currents or firings of BLA inhibitory neurons [21], the inhibitory currents should arise from neighboring inhibitory neurons. Therefore, we examined whether the recorded IPSCs were mediated by the $\mathrm{GABA}_{\mathrm{A}}$ receptor. Indeed, the IPSC was blocked by PTX $(100 \mu \mathrm{M})$, a GABA $\mathrm{A}_{\mathrm{A}}$ receptor antagonist (Fig. 1E and $1 F$ ), which indicates that IPSCs are not evoked through direct activation of the nicotinic receptor on pyramidal neurons but rather by a di-synaptic circuit that includes inhibitory neurons.

Interestingly, MEC-sensitive, di-synaptic IPSC charges (calculated with the integrated area) displayed DSI after $5 \mathrm{sec}$ of depolarization (at $0 \mathrm{mV}$ ) (Fig. 1G, 1H, and 1I). However, the IPSCs gradually reduced, likely due to the desensitization of nicotinic receptor $[22,23]$. It is widely accepted that DSI is mediated mainly by CB1R. Since CB1R is enriched in the presynaptic area of CCK inhibitory neurons in the BLA [24] and di-synaptic IPSC recorded from pyramidal neurons displays asynchronous release (Fig. 1C, 1E and 1I), a known characteristics of synaptic release from CCK inhibitory neurons [25], we assessed the reactivity of CCK 

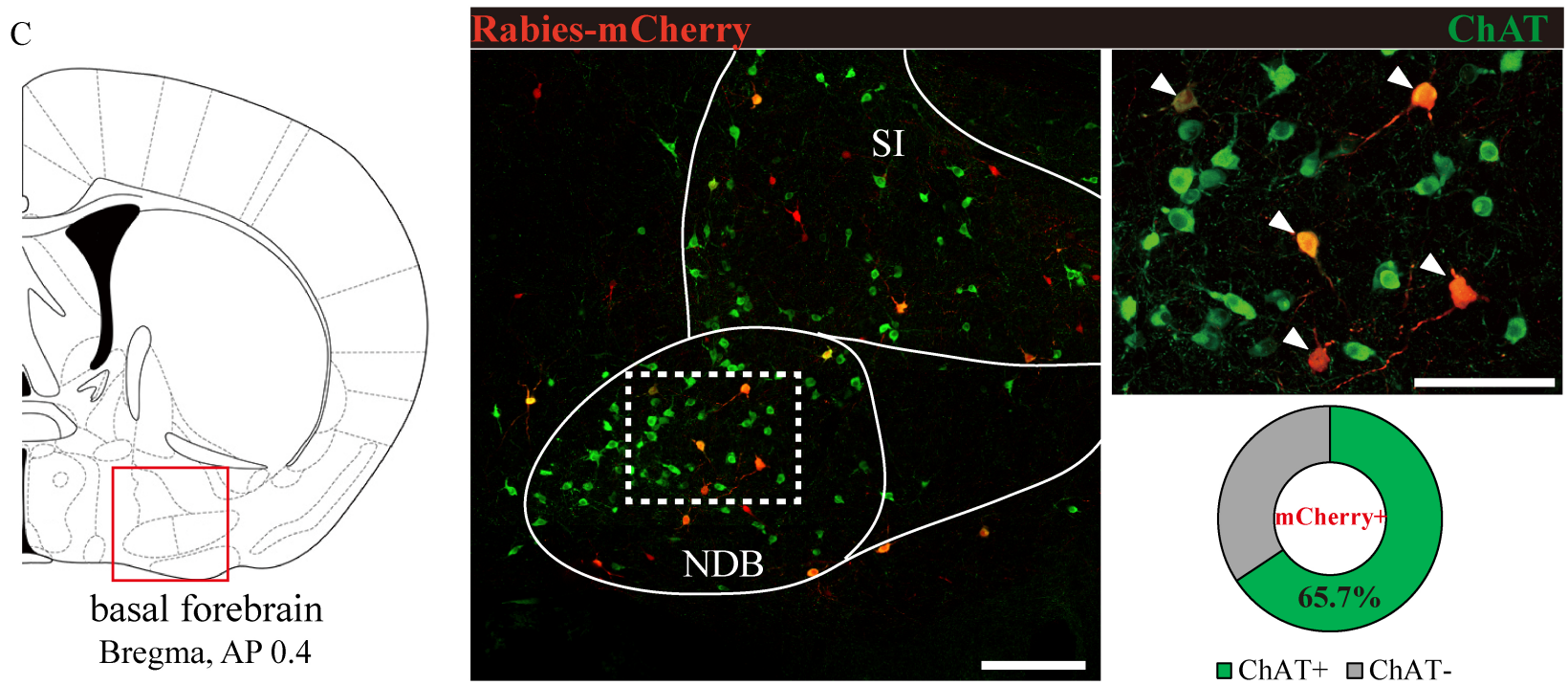

Fig. 4. Continued.

inhibitory neurons to acetylcholine. It was previously shown that Cre expression is not restricted to inhibitory neurons of CCKCre mice [26]. To visualize the CCK inhibitory neurons alone, we expressed a Dlx promoter-driven fluorescent protein in a Credependent manner in the BLA of CCK-Cre mice (Fig. 2A) [27]. Immunochemical analysis revealed that a large proportions of labeled CCK neurons are GABAergic neurons (Fig. 2B and 2C). $36 \%$ of total CCK neurons in the BLA were type L CCK inhibitory neurons (38/106; mean size $\left.=239.3 \pm 8.1 \mu \mathrm{m}^{2}\right)$ (Fig. 2D, 2E, 2F and $2 \mathrm{G}$ ). Type S CCK inhibitory neurons comprised $64 \%$ of total CCK neurons (68/106; mean size $\left.=130.9 \pm 3.1 \mu \mathrm{m}^{2}\right)($ Fig. 2D, 2E, 2F and $2 \mathrm{G}$ ). CCK inhibitory neurons were recorded in a cell-attached configuration (Fig. 3A). Iontophoresis of acetylcholine in proximity to recorded neurons expressing eGFP was sufficient to elicit robust firing of CCK inhibitory neurons (Fig. 3A and 3B), which was resistant to atropine treatment but completely blocked by the addition of MEC (Fig. 3B and 3C). It is of interest that recordings were conducted in the presence of NBQX (or DNQX) and PTX, which indicated that acetylcholine activates CCK inhibitory neurons directly through nicotinic receptors. Although activation of $\mathrm{nAChR}$ in CCK inhibitory neurons seems to be a key factor in disynaptic inhibition in the BLA, the excitation of CCK inhibitory neurons was also induced by activating $\mathrm{mAChR}$ in the hippocampus $[15,16]$. Arguing against this notion, inhibition of $\mathrm{mAChRs}$ did not significantly alter the firing frequency of CCK neurons (Fig. 3C). However, we cannot completely exclude the possibility that cholinergic-induced di-synaptic inhibition could still be mediated by $\mathrm{mAChR}$ in concert with $\mathrm{nAChR}$, but in different temporal windows or at different ligand concentrations.
To determine sources of acetylcholine and upstream regions to BLA CCK inhibitory neurons, we carried out cell type-specific monosynaptic retrograde tracing [28]. TVA is the specific receptor for leukosis virus envelope protein EnvA, which is not naturally expressed in mammalian neurons. Thus, we expressed TVA in CCK inhibitory neurons using a Dlx promoter-driven AAV in CCK-Cre mice [27]. Furthermore, improved rabies glycoprotein $(\mathrm{oG})$ was expressed in the same neurons to allow for trans-synaptic spread of the rabies virus [29]. Then we micro-infused EnvApseudotyped G-deleted rabies virus (EnvA-RV-mCherry) into the same region (Fig. 4A). Viral infection initiated from CCK inhibitory neurons (starter cells) that both expressed TVA (eGFP) and showed infection with the rabies virus (mCherry) (Fig. 4B). Rabies virus was transferred to monosynaptically-connected upstream neurons upto 5 10 days after injection. As a result, dense virusassociated fluorescent signals (mCherry) were detected in several regions, namely the paraventricular nucleus of the thalamus (PVT) (data not shown), substantia innominata (SI), magnocellular nucleus (MA), and diagonal band nucleus (NDB) (Fig. 4C). Most of the traced regions including SI, MA, and NDB are already known to be sources of cholinergic signaling [30]. We further investigated whether those monosynaptically-connected neurons also contained ChAT or not. In the BF, indeed, a large portion of neurons projecting to BLA CCK inhibitory neurons expressed ChAT $(65.7 \% \pm 10.5, \mathrm{~N}=3)$ (Fig. 4C). Therefore, we concluded that BLA CCK inhibitory neurons are functionally and anatomically innervated by BF cholinergic neurons. Taken together, our findings indicate that one of the major upstream effectors exciting BLA CCK inhibitory neurons is BF cholinergic neurons. 
We provide the first evidence that BF cholinergic-induced inhibitory inputs to BLA pyramidal neurons is sensitive to DSI. Therefore, the CCK inhibitory neurons are probably a major source of di-synaptic inhibition evoked by BF cholinergic activation. nAChR appears to play a major role in this di-synaptic circuit and its activation by an endogenous ligand, acetylcholine, is sufficient to evoke action potentials in CCK inhibitory neurons. Viral retrograde tracing revealed that CCK inhibitory neurons are innervated by BF cholinergic neurons. Taken together, BLA CCK inhibitory neurons receive direct inputs from BF cholinergic neurons, which engenders drastic di-synaptic inhibition onto BLA pyramidal neurons. This cholinergic regulation of amygdala neurons would represent the cellular mechanisms whereby emotional memory is maintained or adjusted in response to internal and external changes that animals experience.

\section{ACKNOWLEDGEMENTS}

This work was supported by the National Research Foundation of Korea (2018R1A3B1052079) and KBRI basic research program funded by Ministry of Science and ICT (18-BR-04-01).

\section{REFERENCES}

1. Thiele A (2013) Muscarinic signaling in the brain. Annu Rev Neurosci 36:271-294.

2. Albuquerque EX, Pereira EF, Alkondon M, Rogers SW (2009) Mammalian nicotinic acetylcholine receptors: from structure to function. Physiol Rev 89:73-120.

3. Arroyo S, Bennett C, Hestrin S (2014) Nicotinic modulation of cortical circuits. Front Neural Circuits 8:30.

4. Dannenberg H, Young K, Hasselmo M (2017) Modulation of hippocampal circuits by muscarinic and nicotinic receptors. Front Neural Circuits 11:102.

5. Unal CT, Pare D, Zaborszky L (2015) Impact of basal forebrain cholinergic inputs on basolateral amygdala neurons. J Neurosci 35:853-863.

6. Arroyo S, Bennett C, Aziz D, Brown SP, Hestrin S (2012) Prolonged disynaptic inhibition in the cortex mediated by slow, non- $\alpha 7$ nicotinic excitation of a specific subset of cortical interneurons. J Neurosci 32:3859-3864.

7. Wilson MA, Fadel JR (2017) Cholinergic regulation of fear learning and extinction. J Neurosci Res 95:836-852.

8. Aitta-Aho T, Hay YA, Phillips BU, Saksida LM, Bussey TJ, Paulsen O, Apergis-Schoute J (2018) Basal forebrain and brainstem cholinergic neurons differentially impact amygdala circuits and learning-related behavior. Curr Biol 28:2557- 2569.e4.

9. Jiang L, Kundu S, Lederman JD, López-Hernández GY, Ballinger EC, Wang S, Talmage DA, Role LW (2016) Cholinergic signaling controls conditioned fear behaviors and enhances plasticity of cortical-amygdala circuits. Neuron 90:1057-1070.

10. Zelikowsky M, Hast TA, Bennett RZ, Merjanian M, Nocera NA, Ponnusamy R, Fanselow MS (2013) Cholinergic blockade frees fear extinction from its contextual dependency. Biol Psychiatry 73:345-352.

11. Boccia MM, Blake MG, Baratti CM, McGaugh JL (2009) Involvement of the basolateral amygdala in muscarinic cholinergic modulation of extinction memory consolidation. Neurobiol Learn Mem 91:93-97.

12. Freund TF, Katona I (2007) Perisomatic inhibition. Neuron 56:33-42.

13. Frazier CJ, Rollins YD, Breese CR, Leonard S, Freedman R, Dunwiddie TV (1998) Acetylcholine activates an alphabungarotoxin-sensitive nicotinic current in rat hippocampal interneurons, but not pyramidal cells. J Neurosci 18:11871195.

14. Porter JT, Cauli B, Tsuzuki K, Lambolez B, Rossier J, Audinat E (1999) Selective excitation of subtypes of neocortical interneurons by nicotinic receptors. J Neurosci 19:5228-5235.

15. Karson MA, Tang AH, Milner TA, Alger BE (2009) Synaptic cross talk between perisomatic-targeting interneuron classes expressing cholecystokinin and parvalbumin in hippocampus. J Neurosci 29:4140-4154.

16. Nagode DA, Tang AH, Karson MA, Klugmann M, Alger BE (2011) Optogenetic release of ACh induces rhythmic bursts of perisomatic IPSCs in hippocampus. PLoS One 6:e27691.

17. Kwon OB, Lee JH, Kim HJ, Lee S, Lee S, Jeong MJ, Kim SJ, Jo HJ, Ko B, Chang S, Park SK, Choi YB, Bailey CH, Kandel ER, Kim JH (2015) Dopamine regulation of amygdala inhibitory circuits for expression of learned fear. Neuron 88:378-389.

18. Osakada F, Callaway EM (2013) Design and generation of recombinant rabies virus vectors. Nat Protoc 8:1583-1601.

19. Mascagni F, McDonald AJ (2003) Immunohistochemical characterization of cholecystokinin containing neurons in the rat basolateral amygdala. Brain Res 976:171-184.

20. Dani JA (2015) Neuronal nicotinic acetylcholine receptor structure and function and response to nicotine. Int Rev Neurobiol 124:3-19.

21. Pidoplichko VI, Prager EM, Aroniadou-Anderjaska V, Braga MF (2013) a7-Containing nicotinic acetylcholine receptors on interneurons of the basolateral amygdala and their role in the regulation of the network excitability. J Neurophysiol 110:2358-2369. 
22. Quick MW, Lester RA (2002) Desensitization of neuronal nicotinic receptors. J Neurobiol 53:457-478.

23. Giniatullin R, Nistri A, Yakel JL (2005) Desensitization of nicotinic ACh receptors: shaping cholinergic signaling. Trends Neurosci 28:371-378.

24. Katona I, Rancz EA, Acsady L, Ledent C, Mackie K, Hajos N, Freund TF (2001) Distribution of CB1 cannabinoid receptors in the amygdala and their role in the control of GABAergic transmission. J Neurosci 21:9506-9518.

25. Hefft S, Jonas P (2005) Asynchronous GABA release generates long-lasting inhibition at a hippocampal interneuronprincipal neuron synapse. Nat Neurosci 8:1319-1328.

26. Shen CJ, Zheng D, Li KX, Yang JM, Pan HQ, Yu XD, Fu JY, Zhu Y, Sun QX, Tang MY, Zhang Y, Sun P, Xie Y, Duan S, Hu H, Li XM (2019) Cannabinoid $\mathrm{CB}_{1}$ receptors in the amygdalar cholecystokinin glutamatergic afferents to nucleus accumbens modulate depressive-like behavior. Nat Med 25:337-349.

27. Dimidschstein J, Chen Q, Tremblay R, Rogers SL, Saldi GA,
Guo L, Xu Q, Liu R, Lu C, Chu J, Grimley JS, Krostag AR, Kaykas A, Avery MC, Rashid MS, Baek M, Jacob AL, Smith GB, Wilson DE, Kosche G, Kruglikov I, Rusielewicz T, Kotak VC, Mowery TM, Anderson SA, Callaway EM, Dasen JS, Fitzpatrick D, Fossati V, Long MA, Noggle S, Reynolds JH, Sanes DH, Rudy B, Feng G, Fishell G (2016) A viral strategy for targeting and manipulating interneurons across vertebrate species. Nat Neurosci 19:1743-1749.

28. Wickersham IR, Lyon DC, Barnard RJ, Mori T, Finke S, Conzelmann KK, Young JA, Callaway EM (2007) Monosynaptic restriction of transsynaptic tracing from single, genetically targeted neurons. Neuron 53:639-647.

29. Kim EJ, Jacobs MW, Ito-Cole T, Callaway EM (2016) Improved monosynaptic neural circuit tracing using engineered rabies virus glycoproteins. Cell Reports 15:692-699.

30. Ballinger EC, Ananth M, Talmage DA, Role LW (2016) Basal forebrain cholinergic circuits and signaling in cognition and cognitive decline. Neuron 91:1199-1218. 